\title{
Inhibitory Mechanism of an Extract of Althaea officinalis L. on Endothelin-1-Induced Melanocyte Activation
}

\author{
Akemi Kobayashi, * Akira Hachiya, Atsushi Ohuchi, Takashi Kitahara, and Yoshinori Takema \\ Kao Biological Science Laboratories, 2606 Akabane, Ichikaimachi, Haga, Tochigi 321-3497, Japan. \\ Received March 5, 2001; accepted October 30, 2001
}

\begin{abstract}
It is known that expression of endothelin-1 (ET-1) increases in the epidermis after UVB irradiation, and that this plays an important role during the induction of pigmentation both as a mitogen and as a melanogen for normal human melanocytes (NHMC). When ET-1 acts on NHMC via the endothelin B receptor $\left(E_{B} R\right)$ on their cell surface, mobilization of intracellular calcium is induced, which is followed by activation of Raf-1 located upstream of mitogen activated protein kinase (MAPK). We have continued the search for new agent which inhibit this calcium mobilization and we have found that an extract of Althaea officinalis L. has such an action. In this study, we investigated the precise inhibitory mechanism of this botanical extract on the ET-1-induced activation of melanocytes. Treatment of NHMC with this extract abrogated the stimulatory effect of ET-1 on proliferation and also on activation of MAPK in the intracellular signal transduction pathway, but did not affect the binding of ET-1 to the $\mathrm{ET}_{\mathrm{B}} \mathrm{R}$ or the production of Inositol 1,4,5-Trisphosphate $\left(\mathrm{IP}_{3}\right)$. Further, when this extract was used to treat normal human keratinocytes (NHKC), secretion of ET-1 by those cells was reduced. Taken together, these findings indicate that an extract of $A$. officinalis inhibits both the secretion of ET- 1 from NHKC and the action of ET-1 on NHMC mainly by suppressing the ET-1-induced calcium mobilization without the modification of $\mathrm{IP}_{3}$ production, which in turn suggests that this extract is a useful ingredient for a whitening agent.
\end{abstract}

Key words Althaea officinalis L. extract; endothelin-1; mitogen activated protein kinase; normal human melanocyte

When the skin is irradiated with UVB light, various cytokines are released, act on normal human melanocytes (NHMC), and induce them to synthesize melanin pigment, to proliferate and to differentiate, which leads to increased pigmentation. $^{1-3)}$ Endothelin-1 (ET-1), ${ }^{2,4)}$ basic fibroblast growth factor (b-FGF), ${ }^{5)}$ and $\alpha$-melanocyte-stimulating hormone, ${ }^{6-8)}$ all of which are produced by normal human keratinocytes (NHKC) and are up-regulated following UVB irradiation, act as mitogens for NHMC. Furthermore, an increase in ET-1 expression ${ }^{3)}$ in human skin after UVB irradiation has also been reported, and it has been suggested that ET-1 plays an important role in UVB-induced pigmentation. Therefore, we have investigated various botanical extracts that inhibit the ET-1-induced activation of NHMC. Since intracellular calcium mobilization is induced when ET-1 acts on NHMC, ${ }^{1)}$ we have continued to search for new agents which can block this calcium mobilization and we have found that an extract of Althaea officinalis L. has a potent inhibitory effect. In this study, we have clarified the inhibitory mechanism of the extract of $A$. officinalis on ET-1-induced activation of NHMC.

\section{MATERIALS AND METHODS}

Extract of $A$. officinalis L. A. officinalis is a large perennial plant belonging to the genus hollyhock in the mallow family. Pale pink hollyhock, velvet hollyhock, and marshmallow also belong to this family, and A. officinalis is cultivated for gardening, medication, and food in Europe. The genus name 'Althaea' is derived from 'althaino' in Greek, meaning therapy. The species name 'officinalis' means 'use for drug', and the plant is often prescribed for pain relief and treatment of renal function, inflammation, and irritation syndrome. The portions of the plant used as a drug are the roots and leaves that contain abundant mucus. Marshmallow sweet was originally sipped to treat sore throats, and can be jelled by soak- ing the root powder with sugar in water. We extracted $A$. officinalis roots with a 45\% 1,3-butylene glycol solution and obtained a brown transparent extract, which was used in this evaluation.

Materials NHMC were obtained from KURABO Industries, Ltd. (Osaka, Japan) and NHKC were obtained from Sanko Junyaku Co., Ltd. (Tokyo, Japan). Serum-free NHMC medium (MGM) was purchased from Sanko Pure Chemicals (Tokyo, Japan) and serum-free NHKC medium (SFM) and Dulbecco's modified Eagle's medium (DMEM) were purchased from Gibco Laboratories (Grand Island, NY, U.S.A.). ET derivatives were purchased from Wako Pure Chemical Industries, Ltd. (Tokyo, Japan). Other chemicals were of reagent grade.

Cell Culture NHMC were maintained in MGM supplemented with $1 \mathrm{ng} / \mathrm{ml}$ recombinant b-FGF, $0.5 \mu \mathrm{g} / \mathrm{ml}$ hydrocortisone, $5 \mu \mathrm{g} / \mathrm{ml}$ insulin, $10 \mathrm{ng} / \mathrm{ml}$ phorbol 12 -myristate 13 acetate, $3 \mu \mathrm{g} / \mathrm{ml}$ heparin, antibiotics (50 $\mu \mathrm{g} / \mathrm{ml}$ streptomycin), and $0.2 \%$ bovine pituitary extract (BPE). NHKC were maintained in modified SFM supplemented with $5 \mathrm{ng} / \mathrm{ml}$ epidermal growth factor and $50 \mu \mathrm{g} / \mathrm{ml}$ BPE. B16 F10 melanoma cells are a subline of the pigmented B16 melanoma $(\mathrm{C} 57 \mathrm{BL} / 6 \mathrm{~N})$ and were cultured in DMEM containing 10\% fetal bovine serum. All cells were cultured at $37^{\circ} \mathrm{C}$ with $5 \%$ $\mathrm{CO}_{2}$.

Measurement of Intercellular Calcium Content These techniques were performed according to the method of Yada et al. ${ }^{1)}$ NHMC $\left(1 \times 10^{3}\right.$ cells/well) were loaded with calcium indicator Fura-2/AM $(2 \mu \mathrm{M})$ by incubation for $30 \mathrm{~min}$ at $37^{\circ} \mathrm{C}$ in SFM without supplements. NHMC were washed twice with fresh media and exposed to $5 \mathrm{~nm}$ ET- 1 at $37^{\circ} \mathrm{C}$. The calibration of the fluorescent signal in terms of intracellular calcium content by using a digital imaging microscope.

DNA Synthesis NHMC were seeded in 96-well culture trays at a density of $2 \times 10^{4}$ cells $/ \mathrm{cm}^{2}$ and were cultured for $48 \mathrm{~h}$. Cells were incubated with ET-1 at a concentration of 
$10 \mathrm{~nm} 20 \mathrm{~h}$ later, the cells were labeled for $4 \mathrm{~h}$ with 1.0 $\mu \mathrm{Ci} / \mathrm{ml}\left[{ }^{3} \mathrm{H}\right]$ thymidine. After 3 washes with phosphatebuffered saline (PBS), the cells were trypsinized and harvested on glass fiber filters, washed 3 more times with distilled water, twice with ice-cold ethanol, and then dried. The radioactivity on each filter was directly measured using MATRIX 96 (Packard Bioscience Co.).

Measurement of $\left[{ }^{125}\right.$ I]ET-1 Binding These techniques were performed according to the method of Yada et al. ${ }^{1)}$ NHMC were seeded in 24-well culture trays at a density of $4 \times 10^{4}$ cells $/ \mathrm{cm}^{2}$ and were cultured for $24 \mathrm{~h}$. After washing, binding studies were performed at $4{ }^{\circ} \mathrm{C}$ for $4 \mathrm{~h}$ with $0.4 \mu \mathrm{Ci}$ $\left[{ }^{125} \mathrm{I}\right] \mathrm{ET}-1$ in the presence or absence of unlabeled ET-1 $(0$ $1 \mu \mathrm{M})$. Binding was terminated by washing 3 times with PBS (without $\mathrm{Ca}^{2+}, \mathrm{Mg}^{2+}$ ) and bound $\left[{ }^{125} \mathrm{I}\right] \mathrm{ET}-1$ was determined after solubilization of the cell layer with $1 \mathrm{~N} \mathrm{NaOH}$. Cell-associated radioactivity was measured ${ }^{1)}$ and specific binding was calculated as total binding minus nonspecific binding in the presence of $1 \mu \mathrm{m}$ unlabeled ET- 1 .

Measurement of Inositol 1,4,5-Trisphosphate (IP $)$ These techniques were performed according to the method of Yada et al. ${ }^{1)}$ NHMC were seeded in 24-well culture trays at a density of $6 \times 10^{4}$ cells $/ \mathrm{cm}^{2}$ and were cultured for $48 \mathrm{~h}$. The media were aspirated and modified SFM without supplements, but containing $10 \mathrm{~mm} \mathrm{LiCl}$, was added and incubated for $10 \mathrm{~min}$ at $37^{\circ} \mathrm{C}$ before stimulation. The ligand stimulation was terminated at designated times by adding $10 \%$ perchloric acid and the samples were kept on ice for $15 \mathrm{~min}$. After neutralization with ice-cold $1.5 \mathrm{M} \mathrm{KOH}$ for $60 \mathrm{~min}$ on ice, the samples were centrifuged at $2000 \times \boldsymbol{g}$ for $10 \mathrm{~min}$ to remove $\mathrm{KClO}_{4}$ precipitate. The supernatants were subjected to $\mathrm{IP}_{3}$ assay using an $\mathrm{IP}_{3}$ assay kit (Amersham Pharmacia Biotech, Buckinghamshire, United Kingdom). The content of $\mathrm{IP}_{3}$ in each sample was quantitatively determined from a calibration curve established using the binding protein specific for $\mathrm{IP}_{3}$ and $\left[{ }^{3} \mathrm{H}\right] \mathrm{IP}_{3}$.

Extraction of Cellular Proteins Cells were incubated with ET-1 in 6-well culture trays, then solubilized in $500 \mu \mathrm{l}$ of ice-cold RIPA (radioimmunoprecipitation) buffer containing $50 \mathrm{~mm}$ Tris- $\mathrm{HCl}(\mathrm{pH} 7.5), 150 \mathrm{~mm} \mathrm{NaCl}, 1 \%$ Nonidet P$40,0.25 \% \mathrm{Na}$ deoxycholate, $1 \mathrm{~mm}$ EDTA, $50 \mathrm{~mm} \mathrm{NaF}, 1 \mathrm{~mm}$ sodium orthovanadate, $50 \mathrm{~mm}$ phenylmethylsulfonyl fluoride, and $1 \mathrm{mg} / \mathrm{ml}$ aprotinin. The mixtures were sonicated briefly and were then centrifuged at $14000 \times \boldsymbol{g}$ for $60 \mathrm{~min}$ at $4{ }^{\circ} \mathrm{C}$. Protein concentrations in the supernatants were determined by the BCA assay kit (Pierce Chemical Co., Tokyo, Japan).

Western Blotting To measure mitogen activated protein kinase (MAPK) activity in NHMC, Western blotting was performed according to Imokawa et al. ${ }^{9)}$ Lysates $(20 \mu \mathrm{g} /$ lane $)$ were separated by $10 \%$ sodium dodecyl sulfate-polyacrylamide gel electrophoresis (SDS-PAGE) and then transferred to Immobilon-P PVDF membranes (Millipore, Eschborn, Germany). Membranes were blocked with 3\% bovine serum albumin in Tris-buffered saline containing Tween 20 (TBST) buffer $(20 \mathrm{~mm}$ Tris- $\mathrm{HCl}, \mathrm{pH} 7.2,0.14 \mathrm{M} \mathrm{NaCl}, 0.1 \%$ Tween 20) for $3 \mathrm{~h}$ at room temperature, and were then probed with $\alpha$-phosphospecific ERK1/2 or $\alpha$ ERK1/2 antibodies (New England Biolabs, Inc., MA, U.S.A.) in TBS-T buffer. After washing, blots were incubated with horseradish peroxidase-conjugated secondary antibody (Amersham) for $1 \mathrm{~h}$, and signals were visualized using enhanced chemilumines- cence (ECL) detection reagents (Amersham).

Immuno-Affinity Chromatography Immuno-affinity columns were prepared by covalently linking the anti-peptide IgG to protein A-Sepharose columns using IgG Orientation Kits (Pierce), according to the manufacturer's instructions and as detailed elsewhere. ${ }^{10,11)}$ B16 F10 melanoma cells growing subcutaneously in mice were excised, homogenized gently, and lysed in $155 \mathrm{~mm} \mathrm{NH} \mathrm{NH}_{4} \mathrm{Cl}, 10 \mathrm{~mm} \mathrm{KHCO}_{3}$, and $0.1 \mathrm{~mm}$ EDTA. The cells were washed in ice-cold $\mathrm{PBS}(-)$ and then solubilized in Nonidet P-40/SDS buffer overnight at $4{ }^{\circ} \mathrm{C}$. Identical aliquots ( $\mathrm{ca} .50 \mathrm{mg}$ protein) of the soluble supernatant fraction were bound to each immuno-affinity column and nonabsorbed proteins were washed through with $30-40 \mathrm{ml}$ of Nonidet P-40/SDS buffer. Specifically absorbed proteins were then removed from the column with $10 \mathrm{ml}$ of the elution buffer supplied with the columns. Both the bound and unbound fractions were dialyzed versus $0.01 \%$ Nonidet P-40, $0.01 \mathrm{M}$ Tris buffer, $\mathrm{pH} 7.2$, with phenylmethylsulfonyl fluoride (PMSF) and aprotinin, overnight at $4{ }^{\circ} \mathrm{C}$. These samples were then used for Western blotting for purity analysis, as detailed above, or for assay of melanogenic activities, as detailed below.

Melanogenic Assays (i) Measurement of Dopa Oxidase Activity: These techniques were performed according to Kobayashi et al. ${ }^{12)}$ NHMC were solubilized in extraction buffer [0.1 M Tris- $\mathrm{HCl}$ (pH 7.2), 0.01\% Nonidet P-40, 0.01\% SDS, $100 \mu \mathrm{M}$ PMSF, and $1 \mathrm{mg} / \mathrm{ml}$ aprotinin], and the supernatant after centrifugation at $10000 \times \boldsymbol{g}$ was used as the crude tyrosinase extract in order to measure enzyme activity. Dopa oxidase activity was measured by the 3-methyl-2-benzothiazolinone hydrazone (MBTH) assay, as reported previously. ${ }^{13)}$ The reaction mixture contained assay buffer $(50 \mathrm{~mm}$ sodium phosphate, $\mathrm{pH} 7.1$, and $2 \%$ dimethylformamide), $1 \mathrm{~mm}$ L-dopa and $6 \mathrm{~mm}$ MBTH, at a final $\mathrm{pH}$ of 6.9 . The reaction mixture, without enzyme, was incubated at $37^{\circ} \mathrm{C}$ for $10 \mathrm{~min}$. Dopa oxidase enzyme preparation (the crude tyrosinase) was then added and mixed. Conversion of the substrate dopa to dopaquinone by the crude tyrosinase extract was measured by color reaction with MBTH and the absorbance at $505 \mathrm{~nm}$ was measured. It was monitored spectrophotometrically, routinely over a period of $5 \mathrm{~min}$. Dopa and MBTH were obtained from Sigma Chemical Co. (Saint Louis, Missouri, U.S.A.). (ii) Measurement of dopachrome tautomerase activity: Measurement of dopachrome tautomerase activity was measured by high performance liquid chromatography (HPLC) as the disappearance of dopachrome substrate and the production of 5,6-dihydroxyindole-2-carboxylic acid (DHICA). ${ }^{11,14,15)}$ Dopa-chrome and purified tyrisinase-related protein $2(\mathrm{TRP} 2)^{14)}$ were reacted at $37^{\circ} \mathrm{C}$ for $1 \mathrm{~h}$, and the production of DHICA from the substrate was quantified by HPLC. A C18 reversed phase column was used, and the sample was applied at a flow rate of $0.5 \mathrm{ml} / \mathrm{min}$ using a buffer of $0.15 \mathrm{~m}$ sodium borate buffer $(\mathrm{pH} 2.5)$ and $25 \%$ methanol. Elution of peaks was monitored by $\mathrm{A}_{280}$. Dopachrome substrate was prepared using the silver oxide method originally described by Körner and Pawelek. ${ }^{16)}$

ELISA For ELISA assay to measure ET-1, NHKC were seeded in 48-well culture dishes at a density of $2 \times 10^{4}$ cells $/ \mathrm{cm}^{2}$ and were cultured for $48 \mathrm{~h}$. The medium was then aspirated, exchanged for fresh medium as described above, and the cells were cultured for another $48 \mathrm{~h}$. The conditioned 
medium was collected and quantified in $100 \mu \mathrm{l} /$ well for ET-1 by ELISA. The ET-1 ELISA kit is a solid phase enzyme immunoassay using the multiple antibody sandwich principle. A human purified polyclonal antibody specific for human ET-1 was attached to 96-well microtiter plates. ET-1 in the conditioned media and standards was captured by the solid phase antibody. Horseradish peroxidase-labeled rabbit antihuman ET-1 IgG was then added, which bound to multiple epitopes on ET-1 attached to the solid phase. Levels of immunoreactive ET-1 were measured by absorbance at $450 \mathrm{~nm}$ using a Model 3550 ELISA plate reader (Bio-Rad Laboratories, Hercules, CA, U.S.A.). The amount of ET-1 in the culture media was determined by comparing their absorbance to that produced by standards.

Statistics Statistical analysis was performed by one-way analysis of variance followed by Dunnett's test and a value of $p<0.05$ was considered significant.

\section{RESULTS}

Effect on Mobilization of Intracellular Calcium of NHMC Fura-2/AM fluorescence analysis (Fig. 1) revealed that adding ET-1 to NHMC induced a marked accumulation of intracellular calcium. ${ }^{1)} 5 \mathrm{~nm}$ ET-1 caused NHMC to markedly increase intracellular calcium levels (Fig. 1A), but
A

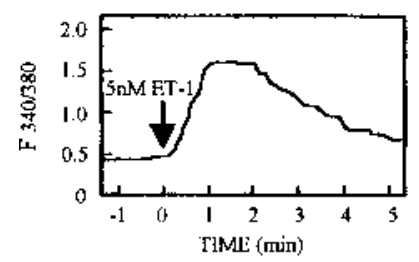

B

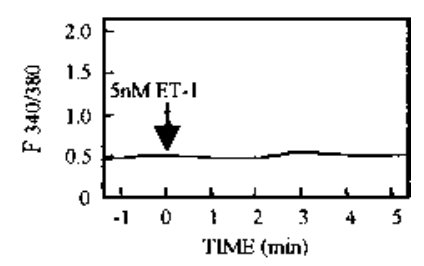

Fig. 1. Effect of the Extract of $A$. officinalis on ET-1-Induced Intracellular Calcium in NHMC

Fura-2/AM-loaded cells were stimulated by the $5 \mathrm{~nm}$ ET-1(A). The extract was added at concentrations of $0.6 \% 1 \mathrm{~h}$ before treatment with $5 \mathrm{~nm}$ ET-1(B). These results are seen as the ratio of the fluorescence emitted at $340 \mathrm{~nm}$ to that emitted at $380 \mathrm{~nm}$. Details are described in Materials and Methods. the pretreatment with the extract of $A$. officinalis completely abolished the intracellular calcium increase of NHMC induced by 5 nм of ET-1 (Fig. 1B).

Effect on Proliferation of NHMC As shown in Fig. 2, the ET-1-induced increase in thymidine uptake ${ }^{1)}$ was inhibited by treatment with the extract of $A$. officinalis in a dosedependent manner, and approximately $50 \%$ of the thymidine uptake was inhibited when $0.5 \%(\mathrm{v} / \mathrm{v})$ of this extract was added. No change in thymidine uptake was noted in the absence of the extract.

In the absence of ET-1, the number of NHMC did not change after addition of $0.05-0.5 \%$ of the extract, confirming that it does not affect proliferation of the cells. When ET1 was added, cell proliferation of NHMC increased, but the increase in the number of the cells was inhibited in a dosedependent manner after addition of $0.05-0.5 \%$ of the extract (Fig. 3, Table 1).

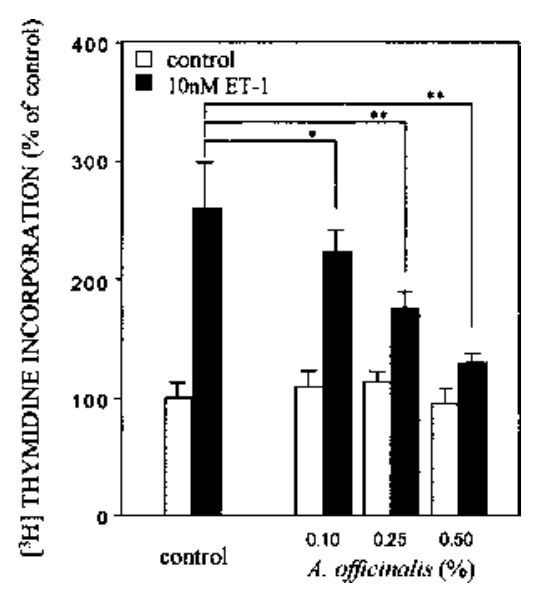

Fig. 2. Inhibitory Effect of the Extract of A. officinalis on DNA Synthesis Induced by ET-1

The extract was added at concentrations of $0.1-0.5 \% 1 \mathrm{~h}$ before treatment with $10 \mathrm{~nm}$ ET-1. DNA synthesis was evaluated by measuring $\left[{ }^{3} \mathrm{H}\right]$ thymidine incorporation for the last $4 \mathrm{~h}$ of the $24 \mathrm{~h}$ incubation with ET-1. Details are described in Materials and Methods. The values reported are means \pm S.E.M. derived from five wells. $* * p<0.01$, $* p<0.05$.
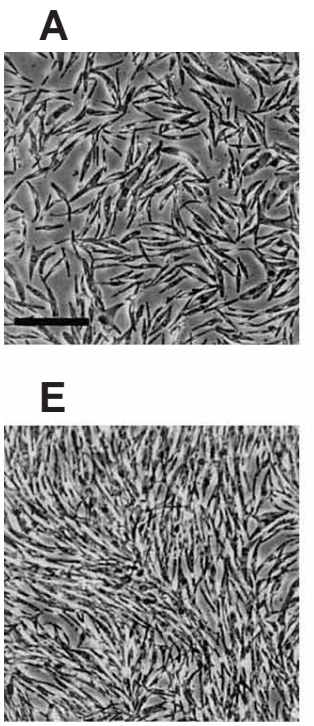
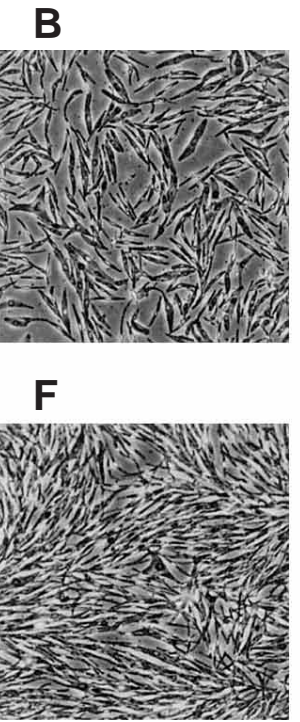
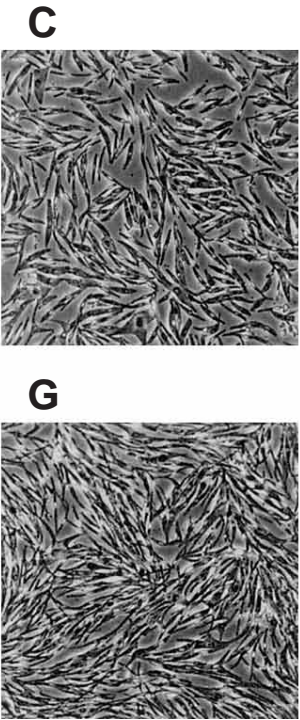
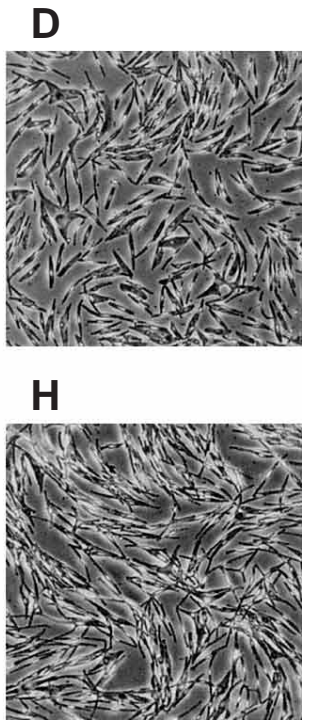

Fig. 3. Microphotographs of Cultured NHMC with or without ET-1 and the Extract of A. officinalis

(A) - (D) without ET-1. (E) - (H) with $10 \mathrm{~nm}$ ET-1. Treated with: (A), (E) $0 \%$ extract; (B), (F) $0.05 \%$ extract; (C), (G) $0.1 \%$ extract; (D), (H) $0.5 \%$ extract. Scale bar: $250 \mu \mathrm{m}$. 
A

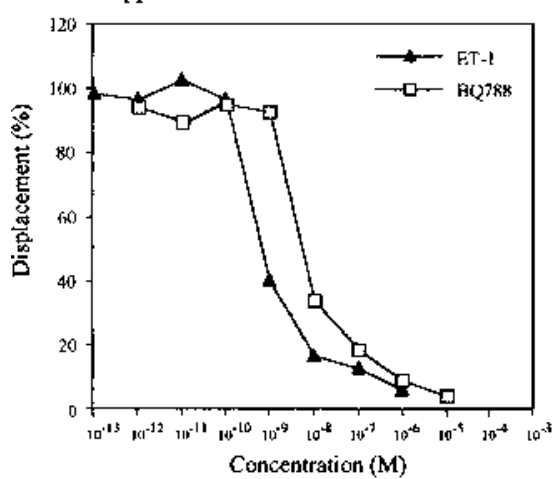

B

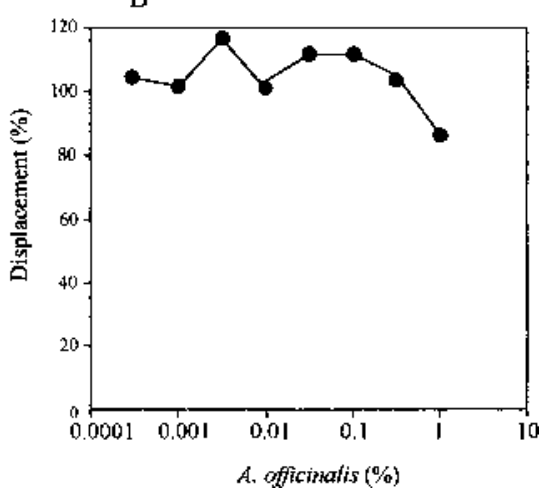

Fig. 4. Effect of the Extract of A. officinalis on Binding of [ $\left.{ }^{125} \mathrm{I}\right] \mathrm{ET}-1$ to NHMC

The $\mathrm{ET}_{\mathrm{B}} \mathrm{R}$ antagonist $\mathrm{BQ} 788$ and ET-1 at concentrations of $1 \mathrm{pm}-10 \mu \mathrm{m}$ were added and incubated for $1 \mathrm{~h}$ at $37^{\circ} \mathrm{C}$ before addition of $\left[{ }^{125} \mathrm{I}\right] \mathrm{ET}-1$ (A). Treated with this extract at concentrations of $0.0003-1 \%$ (B). Details are described in Materials and Methods.

Table 1. Inhibitory Effect of the Extract of $A$. officinalis on the Growth of NHMC

\begin{tabular}{lcccc}
\hline \hline & \multicolumn{4}{c}{ Cell number $\left(\times 10^{4}\right.$ cells $\left./ \mathrm{cm}^{2}\right)$} \\
\cline { 2 - 5 } & \multicolumn{5}{c}{ A. officinalis (\%) } \\
\cline { 2 - 5 } & 0 & 0.05 & 0.1 & 0.5 \\
\hline Non treatment & $17.5 \pm 2.11$ & $16.9 \pm 1.11$ & $16.7 \pm 0.75$ & $15.6 \pm 0.81$ \\
ET-1 10 nM & $26.7 \pm 0.83$ & $25.7 \pm 1.13$ & $21.2 \pm 1.07^{* *}$ & $18.4 \pm 2.43^{* *}$
\end{tabular}

The values reported are means \pm S.E.M. $* * p<0.01$ from $0 \%$ as a control in each treatment.

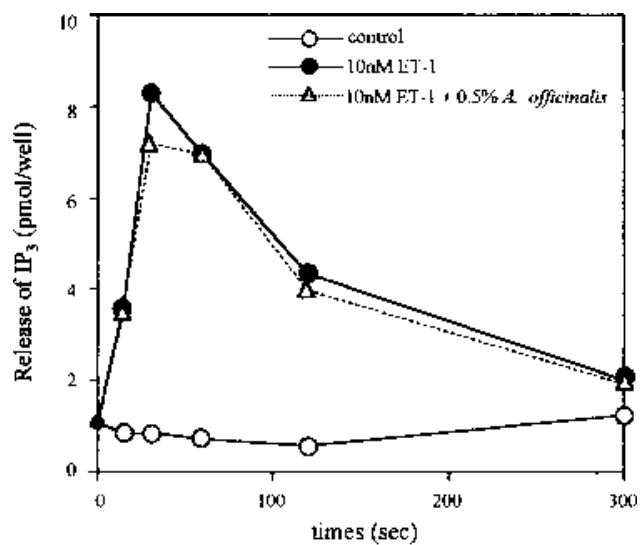

Fig. 5. Effect of the Extract of $A$. officinalis on ET-1-Induced $\mathrm{IP}_{3}$ Production in NHMC

NHMC were incubated with the extract at $0.5 \%$ for $1 \mathrm{~h}$ at $37^{\circ} \mathrm{C}$ before addition of LiCl. Cells were stimulated with $10 \mathrm{~nm}$ ET- 1 for $0-300 \mathrm{~s}$. Details are described in Materials and Methods.

Effect on Signal Transduction in NHMC The binding of ET-1 to its receptor was then examined. The ET-1 receptor $\mathrm{B}$ type inhibitor BQ788 ${ }^{17}$ ) strongly inhibited the binding of ET-1 to the receptor (Fig. 4A), but the extract of $A$. officinalis did not inhibited the binding of ET-1 (Fig. 4B).

Intracellular $\mathrm{IP}_{3}$ production transiently increased and reached a peak $30 \mathrm{~s}$ after stimulation with ET-1 (Fig. 5). The extract of $A$. officinalis did not inhibit the $\mathrm{IP}_{3}$ production.

Next, the effect of the extract on the activation of MAPK was examined. Transient phosphorylation of MAPK was observed 2-6 min after stimulation with ET-1 (data not

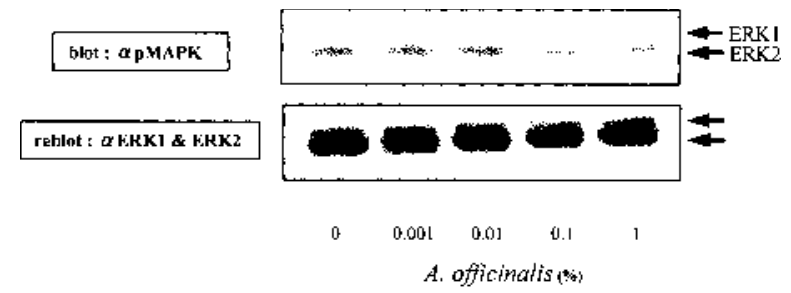

Fig. 6. Inhibitory Effect of the Extract of $A$. officinalis on ET-1-Induced Activation of MAPK

NHMC were incubated with the extract at $0.001-1 \%$ for $1 \mathrm{~h}$ at $37^{\circ} \mathrm{C}$ and then treated with $10 \mathrm{~nm}$ ET-1 for $5 \mathrm{~min}$. The cells were then harvested and solubilized. The activation of MAPK was evaluated by measuring the tyrosine phosphorylation of ERK1/2 by Western blotting using a phospho-specific MAPK antibody, as described in Materials and Methods.

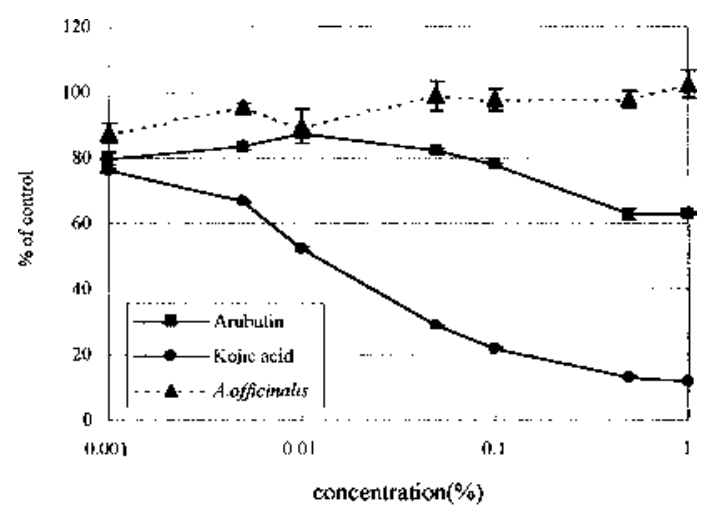

Fig. 7. Effect of the Extract of A. officinalis on Dopa Oxidase Activity, as Measured by the MBTH Assay

Kojic acid, arbutin or the extract was added at concentrations of $0.001-1 \%$ to the reaction mixture. Details are described in Materials and Methods. Kojic acid and arbutin decreased enzyme activity in a dose-dependent manner. Data are expressed as a percentage of the mean of control. The values reported are means \pm S.E.M. derived from three wells.

shown). This ET-1-induced activation of MAPK could be inhibited by the extract of $A$. officinalis (when examined 5 min after stimulation with ET-1), and the inhibitory effect was observed at concentrations of $0.1 \%$ and $1 \%$ (Fig. 6 ).

Effect on Tyrosinase and Tyrosinase-Related Enzymes The effect of the A. officinalis extract on tyrosinase was investigated using the dopa oxidase assay. ${ }^{12)}$ The tyrosinase inhibitor arbutin (Sigma) weakly inhibited the enzyme activity while kojic acid (Tokyo Kasei Industry, Tokyo, Japan) 

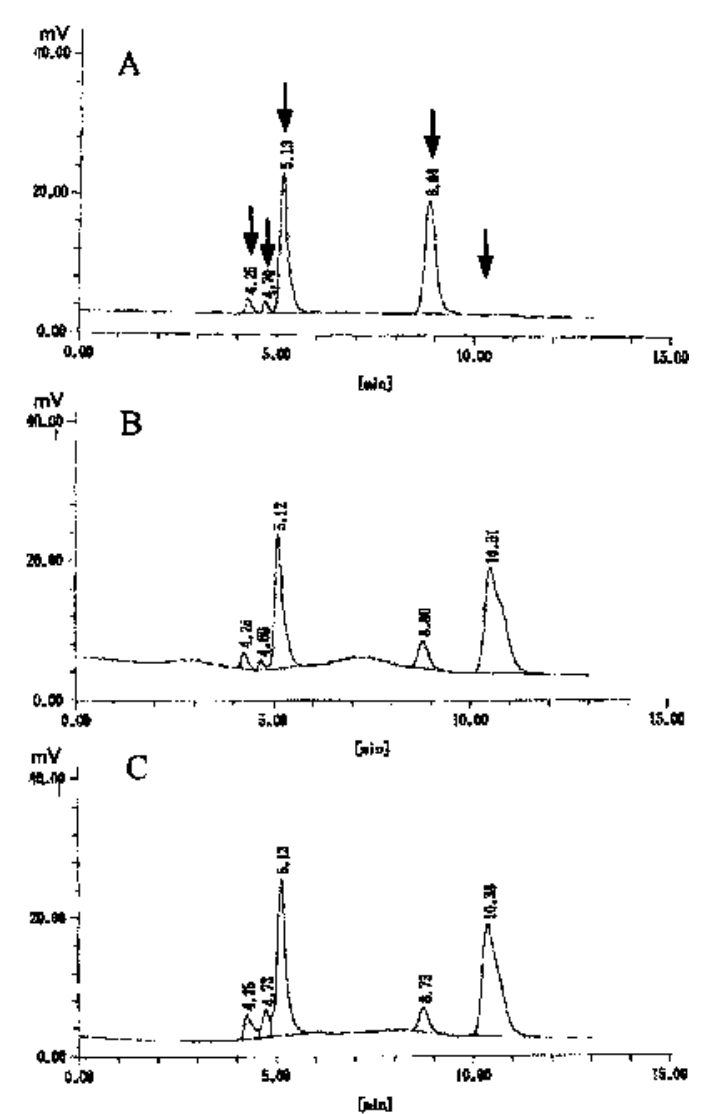

Fig. 8. Effect of the Extract of A. officinalis on Dopachrome Tautomerase Activity

The substrate dopachrome, purified TRP2 and the extract were reacted at $37^{\circ} \mathrm{C}$ for $1 \mathrm{~h}$, and the production of DHICA from the substrate was quantified by HPLC. Dopa elutes at $4.2 \mathrm{~min}$, tyrosine at $4.7 \mathrm{~min}$, dopachrome at $5.1 \mathrm{~min}, 5,6$-dihydroxyindole at $8.8 \mathrm{~min}$, and DHICA at $10.5 \mathrm{~min}$. A, control (buffer only); B, TRP2; C, TRP2 and $1 \%$ of the extract. Details are described in Materials and Methods.

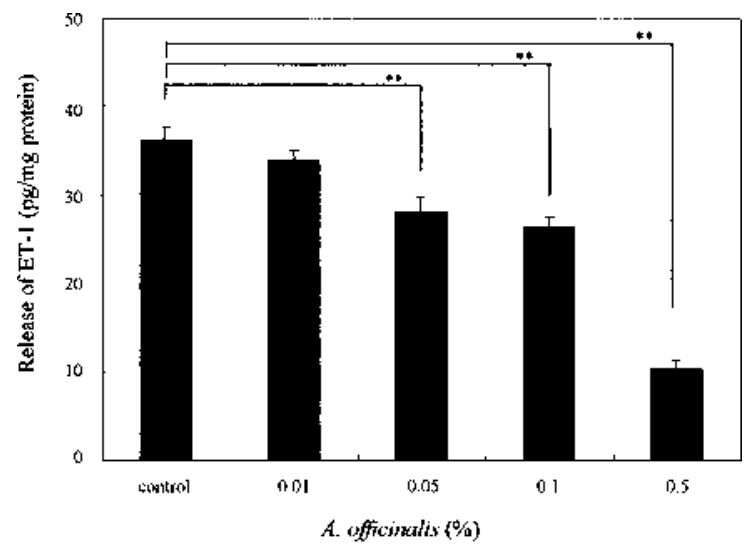

Fig. 9. Inhibitory Effect of the Extract of A. officinalis on ET-1 Production

The extract at concentrations of $0.01-0.5 \%$ was added to NHKC and the cells were cultured for $2 \mathrm{~d}$. The amount of ET- 1 secreted into the culture medium was analyzed by ELISA, as described in Materials and Methods. The values reported are means \pm S.E.M. derived from three wells. $* * p<0.01$ from control.

strongly inhibited it. In contrast, the extract of $A$. officinalis did not inhibit tyrosinase activity (Fig. 7).

The tyrosinase-related enzyme TRP2 has dopachrome tautomerase activity ${ }^{11,18)}$ which results in the conversion of dopachrome to DHICA. The effect of the extract on TRP2 was examined, and the amount of DHICA production did not change after addition of the extract at a concentration of $1 \%$ (Fig. 8).

Effect on ET-1 Production in NHKC ET-1 production in NHKC was inhibited after addition of the extract at concentrations of $0.01-0.5 \%$, in a dose-dependent manner (Fig. 9).

\section{DISCUSSION}

In this study, an extract of $A$. officinalis was found to inhibit intracellular calcium mobilization in NHMC activated by ET-1, and to strongly inhibit ET-1-induced proliferation of melanocytes. These findings suggest that this extract significantly diminishes the physiological effect of ET-1 on NHMC following UVB irradiation. ET-1 is known to activate various intracellular signal transduction pathways in melanocytes. ${ }^{19)}$ ET-1 binds to the $\mathrm{ET}_{\mathrm{B}} \mathrm{R}$ on the melanocyte cell surface and activates phospholipase $\mathrm{C}$ via a $\mathrm{G}$ protein; $\mathrm{IP}_{3}$ and diacylglycerol (DAG) are then produced by inositol phospholipid metabolism. As a result, $\mathrm{IP}_{3}$ releases calcium from the endoplasmic reticulum to increase the intracellular calcium concentration, which activates Raf-1 located upstream of MAPK. DAG has been reported to activate MAPK via protein kinase C. The action of ET-1 is transmitted to stimulate cell proliferation mainly via MAPK., ${ }^{9,20}$ The present study showed that the extract of $A$. officinalis did not affect the intracellular signal transduction pathway located upstream of calcium mobilization, i.e., the binding of ET- 1 to the $\mathrm{ET}_{\mathrm{B}} \mathrm{R}$ on NHMC or the production of $\mathrm{IP}_{3}$. In contrast, the ET-1-induced activation of MAPK was inhibited by the extract. Therefore, the extract of $A$. officinalis is thought to act on both processes of calcium mobilization and of MAPK activation, the sum of which result in the inhibition of ET-1-induced activation of NHMC. When we examined the possibility that this extract directly inhibited tyrosinase and/or tyrosinase-related enzyme activities, the primary targets in whitening cosmetics, it did not inhibit the activity of either enzyme.

In addition to the inhibitory effects of the extract of $A$. officinalis on NHMC, we found that it also inhibited ET-1 secretion from NHKC. Therefore, this extract has dual potential whitening effects by down-regulating keratinocyte and melanocyte function. Since Big ET-1, an inactive precursor of ET-1, is enzymatically cleaved by endothelin-converting enzyme (ECE) to form mature ET-1, it is possible that this botanical extract affects the synthesis or processing of Big ET-1 and thereby reduces ET-1 production by NHKC. The precise mechanism by which this extract regulates ET-1 secretion from NHKC remains to be elucidated.

ET-1 is likely to contribute to UVB-induced pigmentation. Therefore, it is suggested that inhibition of the ET-1-induced activation of NHMC results in the inhibition of pigmentation, and that the extract of $A$. officinalis is a potent ingredient for a whitening agent. Current whitening agents have been developed mainly based on studies of tyrosinase ${ }^{21)}$ in melanocytes, and inhibition of tyrosinase activity has been a primary strategy in the search for whitening agents. However, it may be very difficult for such agents to reach the melanosomes ${ }^{22}$ in which tyrosinase acts at a sufficient dose to be effective. On the other hand, since ET-1 has been reported to promote transcription of tyrosinase, ${ }^{3)}$ this extract might inhibit tyrosinase function by inhibiting its activation 
by ET-1 in addition to its inhibitory effect on melanocyte proliferation, even though the extract does not directly inhibit tyrosinase activity. Therefore, this extract may actually be more effective in reducing tyrosinase function than are the current whitening agents that target tyrosinase. Furthermore, the inhibitory effect of this botanical extract may be enhanced synergistically by combination with other cosmetics.

It has been reported that expression of ET- ${ }^{23)}$ and its receptors is increased ${ }^{24)}$ in seborrhoeic keratosis and in senile pigmented freckles. Involvement of a mechanism similar to the UVB-induced activation of melanocytes has been suggested for these pigmentation disorders, and thus treatment with the extract of $A$. officinalis might also be effective in whitening other than hyperpigmentary conditions associated with ET-1 function.

In conclusion, these findings suggest that the mechanisms involved in the inhibitory effects of the extract of $\mathrm{A}$. officinalis include the inhibition of ET-1-induced activation of the intracellular signal transduction pathway (which inhibits melanocyte proliferation) and also the production of ET-1 in keratinocytes (which inhibits melanocyte differentiation). Therefore, the extract of $A$. officinalis has multiple effective actions and it may be a useful ingredient that inhibits the pigmentation that would normally be stimulated by ET-1 following UVB irradiation.

\section{REFERENCES}

1) Yada Y., Higuchi K., Imokawa G., J. Biol. Chem., 266, 18352-18357 (1991).

2) Imokawa G., Yada Y., Miyagishi M., J. Biol. Chem., 267, 2467524680 (1992).

3) Imokawa G., Miyagishi M., Yada Y., J. Invest. Dermatol., 105, 32-37 (1995).

4) Yohn J. J., Morelli J. G., Walchack S. J., Rundell K. B., Norris D. A., Zamora M. A., J. Invest. Dermatol., 100, 23-26 (1993).

5) Halaban R., Langdon R., Birchall N., Cuono C., Baird A., Scott G.,
Moellmann G., McGuire J., J. Cell. Biol., 107, 1611-1619 (1988).

6) Schauer E., Trautinger F., Kock A., Schwarz A., Bhardwaj R., Simon M., Ansel J. C., Schwarz T., Luger T. A., J. Clin. Invest., 93, 22582262 (1994).

7) Abdel-Malek Z. A., Swope V. B., Suzuki I., Akcali C., Harriger M. D., Boyce S. T., Urabe K., Hearing V. J., Proc. Natl. Acad. Sci. U.S.A., 92, 1789-1793 (1995).

8) Chakraborty A. K., Funasaka Y., Slominski A., Ermak G., Hwang L., Pawelek J., Ichihashi M., Biochim. Biophys. Acta, 1313, 130-138 (1996).

9) Imokawa G., Kobayashi T., Miyagishi M., J. Biol. Chem., 275, $33321-33328$ (2000).

10) Kobayashi T., Urabe K., Winder A., Jiménez-Cervantes C., Imokawa G., Brewington T., Solano F., Garcia-Borron J. C., Hearing V. J., EMBO J., 13, 5818-5825 (1994).

11) Tsukamoto K., Jackson I., Urabe K., Montague P. M,. Hearing V. J., EMBO J., 11, 519-526 (1992).

12) Kobayashi T., Urabe K., Winder A., Tsukamoto K., Brewington T., Imokawa G., Potterf B., Hearing V. J., Pigment Cell Res., 7, 227-234 (1994).

13) Winder A. J., Harris H., Eur. J. Biochem., 198, 317-326 (1991).

14) Kobayashi T., Urabe K., Orlow S. J., Higashi K., Imokawa G., Kwon B. S., Potterf B., Hearing V. J., J. Biol. Chem., 269, 29198-29205 (1994).

15) Palumbo A., d'Ischia M., Misuraca G., Prota G., Biochim. Biophys. Acta, 925, 203-209 (1987).

16) Körner A. M., Pawelek J. M., J. Invest. Dermatol., 75, 192-195 (1980).

17) Ishikawa K., Ihara M., Noguchi K., Mase T., Mino N., Saeki T., Fukuroda T., Fukami T., Ozaki S., Nagase T., Proc. Natl. Acad. Sci. U.S.A., 91, 4892-4896 (1994).

18) Jackson I. J., Chambers D. M., Tsukamoto K., Copeland N. G., Gilbert D. J., Jenkins N. A., Hearing V. J., EMBO J., 11, 527-535 (1992).

19) Halaban R., Pigment. Cell. Res., 13, 4-14 (2000).

20) Imokawa G., Yada Y., Kimura M., Biochem. J., 314, 305-312 (1996).

21) Iozumi K., Hoganson G. E., Pennella R., Everett M. A., Fuller B. B., J. Invest. Dermatol., 100, 806-811 (1993).

22) Mishima Y., Imokawa G., J. Invest. Dermatol., 81, 106-114 (1983).

23) Teraki E., Tajima S., Manaka I., Kawashima M., Miyagishi M., Imokawa G., Brit. J. Dermatol., 135, 918—923 (1996).

24) Tajima S., Manaka I., Kawashima M., Kobayashi T., Imokawa G., J. Invest. Dermatol., 110, 571 (1998). 